(2) Open Access Full Text Article

REVIEW

\title{
Repaglinide/metformin fixed-dose combination to improve glycemic control in patients with type 2 diabetes: an update
}

This article was published in the following Dove Press journal: Diabetes, Metabolic Syndrome and Obesity:Targets and Therapy 10 May 2010

Number of times this article has been viewed

\author{
Robert G Moses \\ Clinical Trials and Research Unit, \\ South East Sydney and Illawarra Area \\ Health Service, New South Wales, \\ Australia
}

\begin{abstract}
Type 2 diabetes is a progressive disease associated with high levels of morbidity and mortality and for which there is both a large and growing prevalence worldwide. Lifestyle advice plus metformin is commonly recommended initially to manage hyperglycemia and to minimize the risk of vascular complications. However, additional agents are required when glycemic targets cannot be achieved or maintained due to the progressive nature of the disease. Repaglinide/metformin fixed-dose combination (FDC) therapy (PrandiMet ${ }^{\mathbb{B}}$; Novo Nordisk, Bagsværd, Denmark) has been approved for use in the USA. This FDC is a rational second-line therapy given the complementary mechanisms of action of the components. Repaglinide is a rapidly absorbed, short-acting insulin secretagogue targeting postprandial glucose excursions; metformin is an insulin sensitizer with a longer duration of action that principally regulates basal glucose levels. A pivotal, 26-week, randomized study with repaglinide/metformin FDC therapy has been conducted in patients experiencing suboptimal control with previous oral antidiabetes therapy. Repaglinide/metformin FDC improved glycemic control and weight neutrality without adverse effects on lipid profiles. There were no major hypoglycemic episodes and patients expressed greater satisfaction with repaglinide/metformin FDC than previous treatments. Repaglinide/metformin FDC is expected to be more convenient than individual tablets for patients taking repaglinide and metformin in loose combination, and it is expected to improve glycemic control in patients for whom meglitinide or metformin monotherapies provide inadequate control.
\end{abstract}

Keywords: type 2 diabetes, metformin, repaglinide, PrandiMet ${ }^{\circledR}$, fixed-dose combination

\section{Introduction}

\section{Prevalence and burden}

Diabetes mellitus is a challenging global health problem, with a large and growing prevalence worldwide and high levels of associated morbidity and mortality. The International Diabetes Federation (IDF) currently forecasts that 380 million people will have diabetes within 20 years, a rise of $55 \%$ from current prevalence estimates. ${ }^{1}$ As $85 \%$ to $95 \%$ of cases of diabetes in the developed world (and higher proportions in the developing world) are type 2, the prevalence forecast for type 2 diabetes in 2025 is effectively in excess of 323 million people. Similar predictions have been made by the World Health Organization. ${ }^{2}$ The rise in prevalence will in part be due to increased life expectancy, as type 2 diabetes is more common in older than younger adults. ${ }^{1}$ However, the rise also reflects ongoing trends towards low levels of physical activity, unhealthy diets and excess body weight. The burden of type 2 diabetes is significant for patients, their carers and healthcare systems. The IDF has commented, "diabetes is expected to
Correspondence: Robert Moses Director of the Illawarra Diabetes Service, Principal Investigator, Clinical Trials and Research Unit, South East Sydney and Illawarra Area Health Service, New South Wales, Australia Tel +6I (02) 423I 1952

Fax +6I (02) 42259452

Email robert.moses@sesiahs.health. nsw.gov.au 
cause 3.8 million deaths worldwide in 2007 , about $6 \%$ of total global mortality, and almost the same as HIV/AIDS." "It also estimates that "the equivalent of ... 23 million years of life are lost to disability and reduced quality of life caused by the complications of diabetes." In financial terms, it is believed that at least US\$232 billion was spent treating and preventing diabetes and its complications globally in 2007, and this is expected to rise to over US\$302 billion by 2025 .

\section{Pathology and symptoms}

Type 2 diabetes is characterized by two underlying defects: insulin resistance in peripheral tissues and reduced insulin secretion due to pancreatic beta cell failure. Insulin resistance remains relatively stable during the course of the disease, but beta cell function continues to decline and is responsible for the progressive nature of type 2 diabetes. ${ }^{3,4}$ In the early stages of beta cell failure there is a reduced insulin response to meals, and thus raised postprandial blood glucose levels. ${ }^{5}$ Chronic elevation of blood glucose levels thereafter has a toxic effect on beta cells, resulting in further reductions in insulin secretion and thus a cycle of increased glucose levels and beta cell damage. Fasting plasma glucose levels become raised as beta cell failure progresses.

The deleterious effects of chronic hyperglycemia are not restricted to pancreatic beta cells. There is also a strong association with micro- and macrovascular complications ${ }^{6}$ and with resultant high levels of mortality and morbidity. The macrovascular complications of coronary heart disease and stroke, for example, are twice as likely to occur in individuals with type 2 diabetes as in those without. ${ }^{7}$ Of the microvascular complications, retinopathy is particularly common, with $74 \%$ of patients with diabetes developing the complication after 10 years or more; neuropathy occurs in approximately half of patients with diabetes and nephropathy in one third. ${ }^{1}$

\section{Treatment}

Stated simply, a key goal of therapy for type 2 diabetes is to achieve and maintain good glycemic control, thus minimizing the risk of diabetes complications. Good glycemic control is generally considered to be a glycated hemoglobin $\left(\mathrm{HbA}_{1 \mathrm{c}}\right)$ level of $<7.0 \%{ }^{8}$ or $<6.5 \%,{ }^{1,9}$ but there is increasing emphasis on separate fasting and postprandial plasma glucose targets. ${ }^{9-11}$ A combination of lifestyle advice (diet and exercise) and metformin is commonly recommended as a first-line therapy for the management of hyperglycemia for patients with type 2 diabetes. ${ }^{8,9}$ Weight loss and increased activity, the goals of lifestyle advice, are associated with significant short- and long-term benefits, and thus form an important part of the therapeutic strategy throughout the course of the disease. The use of metformin at this early stage acknowledges the fact that lifestyle modifications alone are rarely sufficient to maintain glycemic control. Metformin monotherapy is a highly appropriate first-line pharmaceutical intervention as it reduces hyperglycemia without concomitant hypoglycemia or weight gain - side effects that are problematic with hypoglycemic agents.

As type 2 diabetes is progressive, the repeated appraisal of glycemic control is imperative at all stages in the treatment pathway. ${ }^{8,9}$ Where hyperglycemia persists after first-line therapy, it is common practice to add a second agent.

\section{The need for combination therapy}

Dual therapy has an important place in the management of hyperglycemia in type 2 diabetes. The American Association of Clinical Endocrinologists (AACE) and American College of Endocrinology (ACE) advise that monotherapy may initially be sufficient to achieve glycemic goals in patients with $\mathrm{HbA}_{1 \mathrm{c}}$ levels $<7.5 \%$, but that dual therapy should be initiated if monotherapy fails. ${ }^{9}$ For patients with $\mathrm{HbA}_{1 \mathrm{c}}$ levels of $7.6 \%$ to $9.0 \%$, the AACE/ACE advise starting treatment with dual therapy and then progressing to triple and insulin therapies thereafter. ${ }^{9}$

Antihyperglycemic and hypoglycemic drugs with different mechanisms of action are likely to have the greatest efficacy in dual-therapy combinations. ${ }^{8} \mathrm{AACE} / \mathrm{ACE}$ recommend that metformin should be the "cornerstone" of dual therapy for most patients. For patients with $\mathrm{HbA}_{1 \mathrm{c}}$ levels $<7.5 \%$, they recommend (in order) incretin-based therapies, glinides or sulfonylureas as second components. ${ }^{9}$ Glinides are recommended over sulfonylureas because of the need to control postprandial glucose excursions in patients with $\mathrm{HbA}_{1 \mathrm{c}}$ levels $<7.5 \%$ and the better safety profile. For patients with $\mathrm{HbA}_{1 \mathrm{c}}$ levels of $7.6 \%$ to $9.0 \%$, AACE/ACE recommend (in order) incretin-based therapies, thiazolidinediones, sulfonylureas or glinides as second components.

Combination therapy with metformin (an antihyperglycemic drug) and a short-acting insulin secretagogue (an oral hypoglycemic drug), such as repaglinide, is a rational dual-therapy option for type 2 diabetes. Metformin regulates basal glucose levels and repaglinide targets postprandial glucose excursions. The two agents have complementary mechanisms of action and both are agents recommended by AACE/ACE for the management of hyperglycemia in patients with $\mathrm{HbA}_{1 \mathrm{c}}$ levels $<9.0 \%$. Moreover, clinical data have shown that improvements in glycemic control with a loose combination of repaglinide and metformin over a 
4- to 5-month period are both statistically significant and clinically relevant, even after adjusting for improvements in the monotherapy groups. ${ }^{12}$

The concomitant use of repaglinide and metformin has been approved previously, but experience with other dual therapies suggests that fixed-dose combinations (FDCs) can provide greater patient compliance and thus better glycemic control than loose combinations. ${ }^{13,14}$ Repaglinide/metformin FDC (PrandiMet ${ }^{\circledR}$; Novo Nordisk, Bagsværd, Denmark) was approved by the Food and Drug Administration (FDA) in June 2008. Repaglinide/metformin FDC is indicated as an adjunct to diet and exercise to improve glycemic control in adults with type 2 diabetes mellitus who are already treated with a meglitinide and metformin or who have inadequate glycemic control on either meglitinide or metformin alone. ${ }^{15}$ An initial review of the pharmacokinetics, efficacy and safety of this combination product has been published previously. ${ }^{16}$ This article provides further detail and an update following FDA approval and the full publication of key data. This article also considers the potential disadvantages of FDCs as they pertain to the repaglinide/ metformin FDC.

\section{Pharmacology and pharmacokinetics}

The mechanisms of action of repaglinide and metformin, and aspects of their pharmacology and pharmacokinetics, have been reviewed previously. ${ }^{16}$ Additional data are summarized here, along with key points from the previous summary for appropriate context.

\section{Repaglinide}

Repaglinide is a rapidly absorbed, short-acting insulin secretagogue that stimulates insulin secretion in the presence of glucose. Peak plasma levels $\left(\mathrm{C}_{\max }\right)$ occur in healthy volunteers and patients within 1 hour of administration. ${ }^{15}$ The mean time to reach maximum plasma concentrations is unchanged when repaglinide is administered with food, but the mean $\mathrm{C}_{\text {max }}$ and area under the time/plasma concentration curve (AUC) are reduced by $20 \%$ and $12.4 \%$, respectively. The mean absolute bioavailability of repaglinide is $56 \%$ and, after intravenous dosing in healthy volunteers, the volume of distribution at steady state is $31 \mathrm{~L}$ and the total body clearance is $38 \mathrm{~L} /$ hour. Protein binding and binding to human serum albumin are greater than $98 \%$, and the plasma half-life is short (approximately 1 hour). Repaglinide is completely metabolized by oxidative biotransformation and direct conjugation with glucuronic acid, and the resulting metabolites have no antihyperglycemic activity. As CYP2C8 and CYP3A4 are involved in metabolism, drugs that inhibit or induce $2 \mathrm{C} 8$ and/or 3A4 may alter the pharmacokinetics and pharmacodynamics of repaglinide. These drugs include gemfibrozil, trimethoprim, itraconazole, ketoconazole and rifampin. Within 96 hours of dosing with ${ }^{14} \mathrm{C}$-repaglinide, approximately $90 \%$ of the radiolabel is recovered in the feces and approximately $8 \%$ in the urine. Only $0.1 \%$ of the dose is cleared in the urine as parent compound and less than $2 \%$ in feces.

\section{Metformin}

Metformin is an insulin sensitizer that inhibits hepatic glucose output and increases peripheral glucose uptake and utilization. Metformin does not affect insulin secretion. In healthy volunteers, metformin reaches peak plasma levels in 2.8 hours $\left(500 \mathrm{mg}\right.$ or $850 \mathrm{mg}$ tablet). ${ }^{17}$ Metformin $\mathrm{C}_{\max }$ and AUC values are reduced by food (by $40 \%$ and $25 \%$, respectively, for a single $850 \mathrm{mg}$ tablet), and the time to maximum plasma concentrations is delayed (by 35 minutes). ${ }^{15}$ Under fasting conditions, the absolute bioavailability after a $500 \mathrm{mg}$ dose of metformin is approximately $50 \%$ to $60 \%$. Dose proportionality is not apparent due to decreased absorption at higher doses. The high apparent volume of distribution following a single $850 \mathrm{mg}$ dose (averaging $654 \pm 358 \mathrm{~L}$ ) reflects negligible binding to plasma proteins. The plasma elimination half-life is 6.2 hours; the longer blood elimination half-life of 17.6 hours reflects partitioning into erythrocytes. Metformin does not undergo hepatic metabolism or biliary excretion but is excreted unchanged in the urine. Following oral administration, approximately $90 \%$ of the absorbed drug is eliminated via the renal route within the first 24 hours.

\section{Repaglinide/metformin FDC}

The bioequivalence and the effects of food on the pharmacokinetics of the repaglinide/metformin FDC have been investigated in randomized, single-blind, crossover trials in healthy volunteers. ${ }^{18,19}$ Repaglinide and metformin in the higher-dose FDC tablet ( $2 \mathrm{mg} / 500 \mathrm{mg}$ ) were bioequivalent to individual $2 \mathrm{mg}$ repaglinide and $500 \mathrm{mg}$ metformin tablets in terms of total exposure and $\mathrm{C}_{\max } \cdot{ }^{15,18}$ Furthermore, repaglinide total exposure and $\mathrm{C}_{\max }$ values for the higher-dose $\mathrm{FDC}$ tablet were twice those for the lower-dose tablet $(1 \mathrm{mg} / 500 \mathrm{mg})$, indicating dose proportionality. In a separate study of volunteers receiving $2 \mathrm{mg} / 850 \mathrm{mg}$ FDC tablets, food was shown to affect metformin $\mathrm{AUC}$ and $\mathrm{C}_{\max }$ and repaglinide $\mathrm{C}_{\max }$, but not repaglinide AUC. ${ }^{19}$ 


\section{Efficacy}

This section focuses on the recently published full data from the large, randomized, open-label trial of the repaglinide/ metformin FDC. Efficacy data from earlier studies of repaglinide/metformin combination therapy (sometimes referred to as 'loose combination') are also relevant, but have been reviewed previously ${ }^{16}$ and are therefore summarized only briefly here.

\section{Co-administration of repaglinide and metformin}

Studies involving loose combinations of repaglinide and metformin showed that good glycemic control could be attained in patients failing to reach glycemic targets with diet and exercise only or lifestyle advice with up to two oral antidiabetes treatments. These studies provided a strong rationale for the more widespread use of repaglinide plus metformin combination therapy. ${ }^{16}$ Key data from three loose-combination studies are summarized in Table 1. ${ }^{12,20-22}$ In brief, loose-combination therapies provided significantly greater reductions in $\mathrm{HbA}_{1 \mathrm{c}}$ levels than repaglinide and metformin monotherapies ${ }^{12,20,22}$ and the reduction with one combination therapy was significantly greater than the sum of the reductions for the monotherapies (Figure 1). ${ }^{12}$ Reductions in $\mathrm{HbA}_{1 \mathrm{c}}$ levels were also greater with repaglinide + metformin than with nateglinide + metformin combination therapy. ${ }^{21}$ Similar effects were apparent for comparisons of fasting plasma glucose levels. ${ }^{12,20-22}$

\section{Repaglinide/metformin FDC therapy}

The efficacy of repaglinide/metformin FDC tablets has been investigated in a pivotal, 26-week study. ${ }^{23,24}$ The active comparator in this trial was another metformin-based FDC, but with an insulin sensitizer, rosiglitazone, rather than an insulin secretagogue.

\section{Study design}

Participants enrolled into the study had been previously receiving up to two oral antidiabetes drugs (for at least 2 months as monotherapy) and experiencing suboptimal glycemic control $\left(\mathrm{HbA}_{1 \mathrm{c}}\right.$ levels of $7.5 \%$ to $11.0 \%$ for monotherapy or $7.0 \%$ to $10.0 \%$ for dual therapy). Any drug other than metformin must have been administered at half-maximal doses or less. A total of 561 patients were randomly allocated 1:1:1 to repaglinide/metformin FDC twice or three times daily, or rosiglitazone/metformin twice daily $(n=187$ in each group). The repaglinide/metformin FDC groups received maximum doses of either $4 \mathrm{mg}$ repaglinide/1,000 mg metformin at breakfast and supper (twice daily regimen) or $4 \mathrm{mg}$ repaglinide/1,000 mg metformin at breakfast and supper and $2 \mathrm{mg}$ repaglinide $/ 500 \mathrm{mg}$ metformin at lunch (three times daily regimen). The rosiglitazone/metformin group received maximum doses of $4 \mathrm{mg}$ rosiglitazone/1,000 $\mathrm{mg}$ metformin at breakfast and supper. Doses were titrated weekly over a 4-week period up to the maximum doses. Patients who were unable to tolerate dosing were withdrawn from the

Table I Glycemic control in terms of $\mathrm{HbA}_{\mathrm{lc}}$ levels from key studies involving the co-administration of repaglinide and metformin (loose combination) in patients with type 2 diabetes

\begin{tabular}{|c|c|c|c|}
\hline Reference & Patient population & Overview of study design & Key efficacy findings \\
\hline $\begin{array}{l}\text { Moses et al }{ }^{12} \\
\text { and Moses et } \mathrm{al}^{20}\end{array}$ & $\begin{array}{l}\text { Suboptimal glycemic control } \\
\text { after } 6 \text { months of metformin } \\
\text { monotherapy }\end{array}$ & $\begin{array}{l}4-5 \text { months of treatment with: } \\
\text { repaglinide + placebo }(n=29) \\
\text { placebo }+ \text { metformin }(n=27) \\
\text { repaglinide + metformin }(n=27)\end{array}$ & $\begin{array}{l}\text { Mean } \mathrm{HbA}_{\mathrm{Ic}} \text { levels significantly reduced from baseline } \\
\text { with repaglinide }+ \text { metformin }(P<0.0 \mathrm{I}) \text {; reductions } \\
\text { with monotherapies not significant } \\
\text { Reduction in } \mathrm{HbA}_{\mathrm{Ic}} \text { level with repaglinide }+ \text { metformin } \\
\text { significantly greater than those with monotherapies } \\
(P<0.05 \text { in each case), and reduction numerically } \\
\text { greater than the sum of the effects for each monotherapy } \\
\text { More patients in the repaglinide }+ \text { metformin group } \\
(56 \%) \text { achieved } \mathrm{HbA}_{\mathrm{Ic}} \text { target levels of }<7.0 \% \text { than in } \\
\text { the monotherapy groups ( } 19 \% \text { in each case) }\end{array}$ \\
\hline Reboussin et $\mathrm{al}^{22}$ & $\begin{array}{l}\text { Suboptimal glycemic control } \\
\text { with diet and exercise or } \\
\text { with fewer than three OADs }\end{array}$ & $\begin{array}{l}\text { I } 6 \text { weeks of treatment with: } \\
\text { repaglinide }(n=44) \\
\text { repaglinide }+ \text { metformin }(n=42)\end{array}$ & $\begin{array}{l}\text { Reductions in } \mathrm{HbA}_{\mathrm{Ic}} \text { levels from baseline significant } \\
\text { for both groups }(P<0.00 \mathrm{I}) \\
\text { Change from baseline in } \mathrm{HbA} \text { lc level greater with } \\
\text { repaglinide }+ \text { metformin than with repaglinide } \\
\text { monotherapy }(P<0.05)\end{array}$ \\
\hline Raskin et $\mathrm{al}^{21}$ & $\begin{array}{l}\text { Suboptimal glycemic control } \\
\text { with OAD monotherapy } \\
\text { or glyburide/metformin } \\
\text { combination therapy }\end{array}$ & $\begin{array}{l}\text { I } 6 \text { weeks of treatment with: } \\
\text { repaglinide }+ \text { metformin }(n=96) \\
\text { nateglinide }+ \text { metformin }(n=96)\end{array}$ & $\begin{array}{l}\mathrm{HbA}_{\mathrm{Ic}} \text { reduction with repaglinide }+ \text { metformin significantly } \\
\text { greater than that for nateglinide }+ \text { metformin }(P<0.00 \mathrm{I}) \\
\text { More patients in the repaglinide }+ \text { metformin group } \\
(59 \%) \text { achieved } \mathrm{HbA}_{\mathrm{Ic}} \text { target levels of } \leq 7.0 \% \text { than in the } \\
\text { nateglinide }+ \text { metformin group }(47 \%)\end{array}$ \\
\hline
\end{tabular}

Abbreviations: $\mathrm{HbA}_{1 \mathrm{c}}$, glycated hemoglobin; OAD, oral antidiabetes drug. 


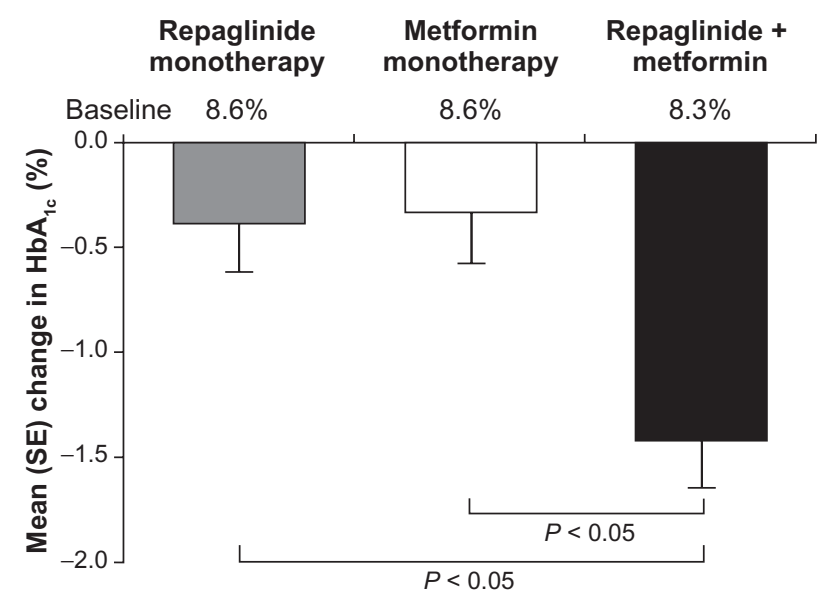

Figure I Mean changes in glycated hemoglobin $\left(\mathrm{HbA}_{\mathrm{lc}}\right)$ levels from baseline in patients receiving repaglinide or metformin monotherapies or repaglinide + metformin combination therapy. Drawn from data of Moses et al, 1999. ${ }^{12}$

study. The efficacy of repaglinide/metformin twice daily was compared with those of the other two treatment regimens. Parameters assessed included glycemic control $\left(\mathrm{HbA}_{1 \mathrm{c}}\right.$ and fasting plasma glucose levels), body weight, waist:hip ratios and lipid profiles. The primary endpoint was the change in $\mathrm{HbA}_{1 \mathrm{c}}$ level from baseline to week 26.

\section{Patient disposition and baseline characteristics}

A total of $383(68.3 \%)$ patients completed the study. Discontinuation rates were similar across the treatment groups, but withdrawal because of ineffective therapy was slightly more common with rosiglitazone/metformin and withdrawal for adverse events slightly more common with repaglinide/metformin. ${ }^{24}$ The treatment groups were comparable in terms of baseline demographic and disease characteristics. The study population had mean ages across the treatment groups of 54.5 to 54.8 years, and mean body mass indices of 32 to $33 \mathrm{~kg} / \mathrm{m}^{2}$. The mean durations of diabetes were 7.1 to 7.4 years and the mean baseline $\mathrm{HbA}_{1 \mathrm{c}}$ values were $8.3 \%$ to $8.5 \%$.

\section{Repaglinide/metformin FDC twice versus three times daily}

Both regimens improved $\mathrm{HbA}_{1 \mathrm{c}}$ levels during the study (Figure 2), with overall mean reductions from baseline to week 26 of $-0.99 \%$ and $-1.02 \%$ for the twice and three times daily regimens, respectively. ${ }^{23}$ Importantly, the twice daily regimen was non-inferior to the three times daily regimen (least square mean, $0.122 ; 95 \%$ confidence interval $[\mathrm{CI}]:-0.104$ to 0.349 ). Improvements in glycemic control were reflected in the proportions of patients reaching target $\mathrm{HbA}_{1 \mathrm{c}}$ levels. At week $26,42.9 \%$ and $48.9 \%$ of the twice and three times

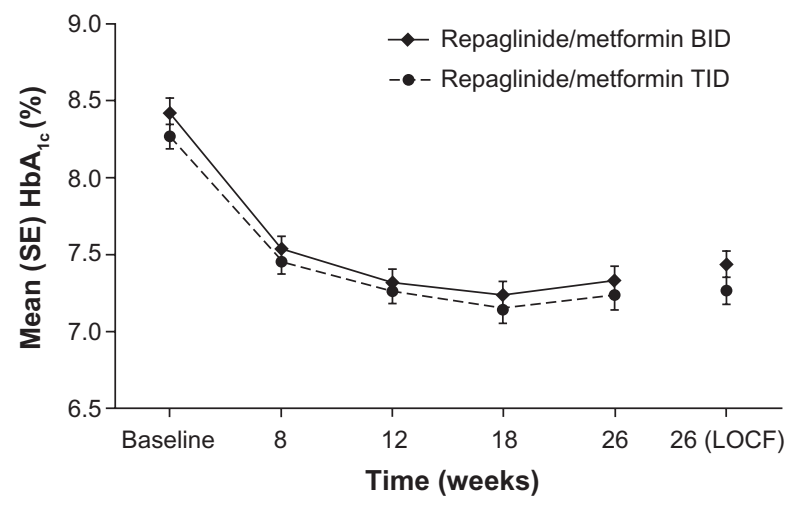

Figure 2 Glycated hemoglobin $\left(\mathrm{HbA}_{\mathrm{lc}}\right)$ values by study visit for repaglinide/ metformin twice daily (BID) and three times daily (TID) fixed-dose combination regimens. Raskin P, Lewin A, Reinhardt R, Lyness W, for the repaglinide/metformin fixed-dose combination study group. Twice-daily and three-times-daily dosing of a repaglinide/metformin fixed-dose combination tablet provide similar glycemic control. Diab Obes Metab. 2009; I 1:947-952. ${ }^{23}$ Reprinted with permission from John Wiley \& Sons Inc.

Abbreviation: LOCF, last observation carried forward.

daily groups, respectively, had $\mathrm{HbA}_{1 \mathrm{c}}$ levels of $\leq 7.0 \%$. There was no significant difference between the treatment regimens in terms of the proportions of patients reaching this or the $\leq 7.5 \%$ or $\leq 6.5 \% \mathrm{HbA}_{1 \mathrm{c}}$ targets. The pattern of reductions in fasting plasma glucose levels was similar to that for $\mathrm{HbA}_{1 \mathrm{c}}$ levels (Figure 3). Moreover, the changes from baseline to week 26 were not significantly different for the two regimens $(P=0.3472)$. Mean reductions in fasting plasma glucose levels were $-1.13 \mathrm{mmol} / \mathrm{L}$ and $-1.10 \mathrm{mmol} / \mathrm{L}$ for the twice and three times daily regimens, respectively.

In essence, the regimens were weight-neutral, with a small mean weight gain of $0.47 \mathrm{~kg}$ in the twice daily group

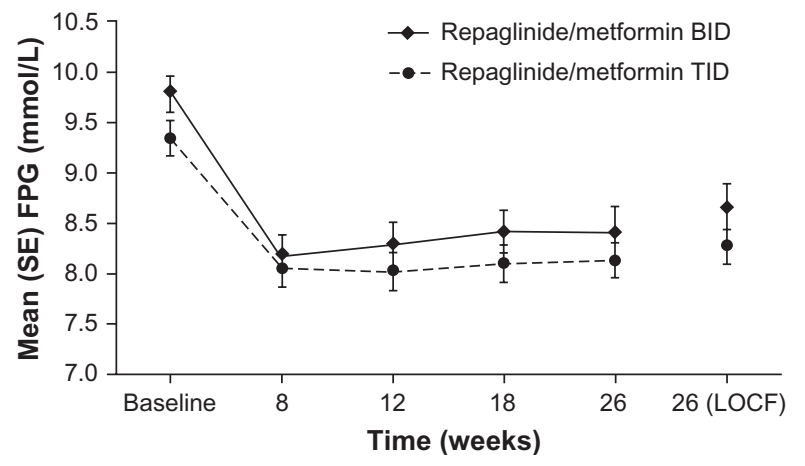

Figure 3 Fasting plasma glucose (FPG) values by study visit for repaglinide/ metformin twice daily (BID) and three times daily (TID) fixed-dose combination regimens. Raskin $\mathrm{P}$, Lewin A, Reinhardt R, Lyness W, for the repaglinide/metformin fixed-dose combination study group. Twice-daily and three-times-daily dosing of a repaglinide/metformin fixed-dose combination tablet provide similar glycemic control. Diab Obes Metab. 2009; I I:947-952. ${ }^{23}$ Reprinted with permission from John Wiley and Sons Inc.

Abbreviation: LOCF, last observation carried forward. 
compared with a small mean weight loss of $-0.34 \mathrm{~kg}$ in the three times daily group. The difference between the groups was statistically significant $(P=0.0333)$, but not clinically relevant. Moreover, there was no significant difference between the two regimens for waist:hip ratios $(P=0.5438)$. Long-term weight-neutrality is expected with repaglinide/metformin combination therapy based on extensive clinical experience with metformin monotherapy, and 1-year double-blind clinical trial data with repaglinide monotherapy. ${ }^{25-27}$

Overall, the efficacy data from the study suggest that repaglinide/metformin FDC can be administered in a twice or three times daily regimen, depending on individual patient needs, without compromising efficacy. This FDC may also be an appropriate therapeutic option for patients with type 2 diabetes who have fears about weight gain when intensifying their oral antidiabetes therapy.

\section{Repaglinide/metformin twice daily versus rosiglitazone/metformin twice daily}

The improvement in $\mathrm{HbA}_{1 \mathrm{c}}$ levels at study end for repaglinide/ metformin was non-inferior to that for rosiglitazone/metformin $(-0.99 \%$ and $-1.01 \%$, respectively; $P=0.8186) .{ }^{24}$ During the course of the study, however, reductions occurred earlier with repaglinide/metformin than rosiglitazone/metformin (Figure 4). At week 26, 42.9\% and $48.9 \%$ of the repaglinide/ metformin and rosiglitazone/metformin groups, respectively, had $\mathrm{HbA}_{1 \mathrm{c}}$ levels of $\leq 7.0 \%$. There was no significant difference between the treatment regimens in terms of the proportions of patients reaching this or the $\leq 7.5 \%$ or $\leq 6.5 \%$ $\mathrm{HbA}_{1 \mathrm{c}}$ targets. Fasting plasma glucose levels improved in both treatment groups but rosiglitazone/metformin was associated with significantly greater reductions than repaglinide/

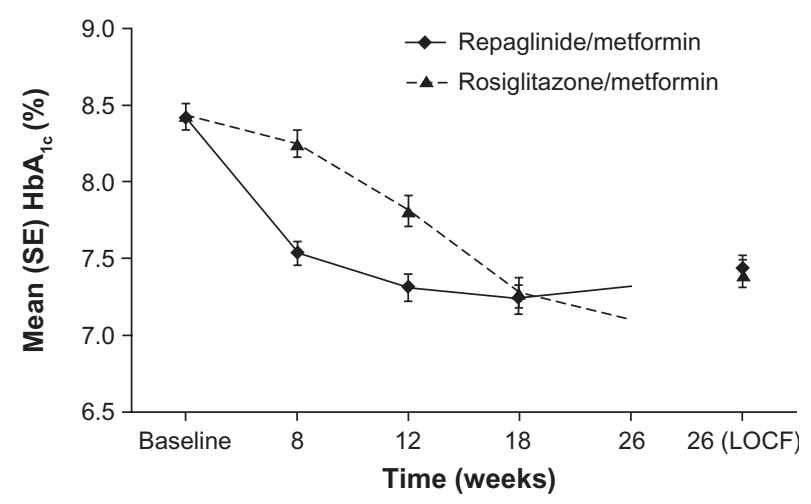

Figure 4 Glycated hemoglobin $\left(\mathrm{HbA}_{\mathrm{Ic}}\right)$ values by study visit for repaglinide/ metformin and rosiglitazone/metformin twice daily fixed-dose combination regimens. Raskin P, Lewin A, Reinhardt R, Lyness W; for the repaglinide/metformin fixeddose combination study group. Twice-daily dosing of a repaglinide/metformin fixeddose combination tablet provides glycemic control comparable to rosiglitazone/ metformin tablet. Diab Obes Metab. 2009; I I:865-873. ${ }^{24}$ Reprinted with permission from John Wiley \& Sons Inc.

Abbreviation: LOCF, last observation carried forward.

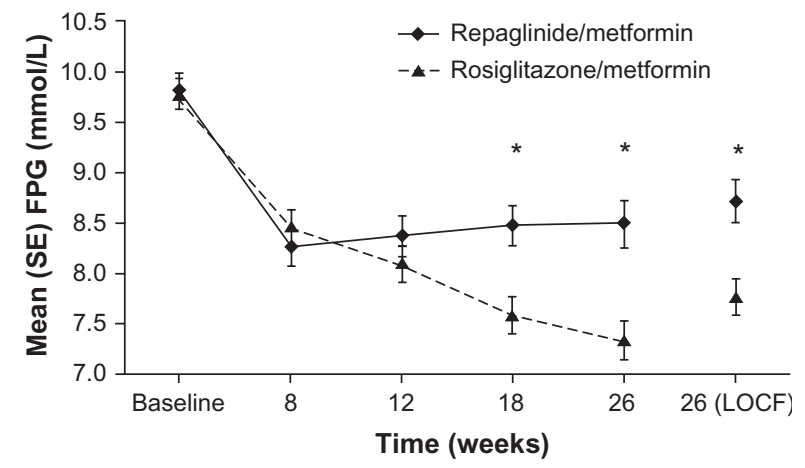

Figure 5 Fasting plasma glucose (FPG) values by study visit for repaglinide/metformin and rosiglitazone/metformin twice daily fixed-dose combination regimens. $* P<0.05$ for between-group differences in change in FPG. Raskin P, Lewin A, Reinhardt R, Lyness $\mathrm{W}$; for the repaglinide/metformin fixed-dose combination study group. Twice-daily dosing of a repaglinide/metformin fixed-dose combination tablet provides glycemic control comparable to rosiglitazone/metformin tablet. Diab Obes Metab. 2009; I 1:865-873.24 Reprinted with permission from John Wiley \& Sons Inc. Abbreviation: LOCF, last observation carried forward.

metformin at weeks 18 and 26 (Figure 5). At week 26, the changes for the rosiglitazone/metformin and repaglinide/ metformin groups were $-2.04 \mathrm{mmol} / \mathrm{L}$ and $-1.13 \mathrm{mmol} / \mathrm{L}$, respectively $(P=0.004)$. These differences between treatment groups may be due to the mechanisms of action of repaglinide and rosiglitazone. Repaglinide is a short-acting insulin secretagogue commonly used to reduce mealtime glucose excursions, whereas rosiglitazone is an insulin sensitizer, which may be expected to have a greater effect on fasting plasma glucose levels.

Changes in body weight and waist:hip ratios were not clinically relevant $(<0.5 \mathrm{~kg})$ and not statistically different between groups. There were small (although not significant) reductions from baseline with repaglinide/metformin for all lipids measured but significant increases $(P \leq 0.001)$ with rosiglitazone/metformin for all lipids measured except triglycerides.

Over a 26-week period, the repaglinide/metformin and rosiglitazone/metformin FDCs used in this study provided similar levels of glycemic control in terms of $\mathrm{HbA}_{1 \mathrm{c}}$ levels and both were weight-neutral. While rosiglitazone/metformin provided better control of fasting plasma glucose levels, there were also adverse effects on lipid profiles.

\section{Appraisal of current research}

There are currently few studies with repaglinide/metformin FDC. The key study reported above was a large, randomized, controlled trial and as such provides valuable data about the efficacy and safety of repaglinide/metformin FDC. The open-label nature of the study may have influenced study outcomes, although the key findings are in line with expectations based on clinical experience and clinical trial 
data with loose combination therapy. It is hoped that future research will investigate whether the efficacy benefits of repaglinide/metformin FDC are maintained in the longer term.

\section{Dosing strategy}

The potential benefits afforded by FDCs in terms of patient convenience and compliance must be weighed against the potential disadvantage of reduced dosing flexibility (such that patients are at an increased risk of adverse effects without added benefit). Repaglinide/metformin FDC is available in two dose strengths, $1 \mathrm{mg}$ repaglinide/500 mg metformin and $2 \mathrm{mg}$ repaglinide $/ 500 \mathrm{mg}$ metformin. ${ }^{15}$ For patients already taking repaglinide and metformin in loose combination, doses should be matched to FDC doses. Patients experiencing suboptimal glycemic control with metformin or meglitinide monotherapy are candidates for dual therapy. ${ }^{9}$ Where the repaglinide/metformin FDC appears the most appropriate choice for that dual therapy, treatment should usually be started with the low-dose tablet twice daily. ${ }^{15}$

Physicians will also be familiar, based on their experience with other treatment options, with the need to monitor blood glucose levels to determine the therapeutic response and advise patients on the appropriate use of treatment in relation to meals. In the case of the repaglinide/metformin FDC, treatment should be administered within the 15 minutes preceding a meal, but the timing can vary from immediately preceding the meal to up to 30 minutes before the meal. Patients who skip a meal should be advised to skip the dose for that meal. Maximum doses are $10 \mathrm{mg}$ repaglinide $/ 2500 \mathrm{mg}$ metformin per day or $4 \mathrm{mg}$ repaglinide/1000 $\mathrm{mg}$ metformin per meal, and treatment can be administered two or three times daily. Indeed, data from the clinical study conducted by Raskin and colleagues have shown that reductions in $\mathrm{HbA}_{1 \mathrm{c}}$ and fasting plasma glucose over 26 weeks with a twice daily regimen were not significantly different from those for the three times daily regimen. ${ }^{23}$

\section{Safety and tolerability Individual components}

The individual components of the repaglinide/metformin FDC are generally well tolerated. ${ }^{28,29}$ As with all insulin secretagogues, repaglinide has the potential to cause hypoglycemia. However, the risk of major hypoglycemia with repaglinide may be lower than that with sulfonylureas, ${ }^{30}$ and the risk can be minimized by matching the dose with the correct carbohydrate meal portions and by initiating treatment with the lowest available dose in patients naïve to meglitinide therapy. Metformin is not associated with hypoglycemia; moreover, it lowers blood glucose levels without causing weight gain and has neutral-to-positive effects on lipids and blood pressure. ${ }^{31}$

Metformin is associated with more gastrointestinal symptoms than other oral antidiabetes drugs (eg, nausea, vomiting, diarrhea), ${ }^{32}$ but these symptoms can be limited by reducing the dose and using slow-release formulations. Additionally, although metformin accumulation can lead to lactic acidosis, this adverse event is rare, with an incidence of 0.03 cases $/ 1,000$ patient-years of exposure. ${ }^{33}$ Moreover, in more than 20,000 patient-years of exposure to metformin in clinical trials, there were no reports of lactic acidosis. As metformin is largely excreted by the kidneys, the risk of metformin accumulation is greater in patients with renal impairment. Metformin is thus contraindicated in patients with renal impairment.

The incidence of total serious cardiovascular adverse events is $4 \%$ for repaglinide and 3\% for sulfonylurea drugs in 1-year controlled clinical trials. ${ }^{15}$ Initial data from a nationwide study in Denmark among 100,206 patients with diabetes without prior myocardial infarction suggest repaglinide monotherapy is associated with a risk of cardiovascular death similar to metformin monotherapy, the drug considered to be the safest glucose-lowering agent in terms of cardiovascular disease. ${ }^{34}$ The risks of cardiovascular death for acarbose and the sulfonylurea gliclazide were also similar to those for metformin, but the risks were higher for the other sulfonylureas tested (glimepiride, glibenclamide, glipizide and tolbutamide).

\section{Repaglinide/metformin combination therapy}

Combination therapy is well tolerated. The safety of repaglinide/metformin FDC was investigated in a large, 26-week study of patients experiencing suboptimal glycemic control with one or two oral antidiabetes drugs. ${ }^{23,24}$ The study had three treatment arms: repaglinide/metformin FDC twice or three times daily, and rosiglitazone/metformin FDC twice daily. A slightly higher proportion of patients withdrew because of adverse events from repaglinide/metformin FDC regimens $(9.6 \%$ and $9.1 \%$ for twice and three times daily, respectively) than the rosiglitazone/metformin FDC regimen (6.4\%), but the proportions of patients experiencing adverse events overall were similar across treatment arms (54.3\%, $63.4 \%$ and $58.9 \%$, respectively). The most common adverse events with the twice daily repaglinide/metformin regimen were diarrhea $(10.6 \%)$, headache $(6.4 \%)$, upper respiratory 
tract infection (4.8\%) and nausea (4.8\%). Similar rates were observed with the three times daily regimen, although the rate for upper respiratory tract infection was lower $(2.2 \%)$. Diarrhea and headache were less common with rosiglitazone/ metformin FDC, but the adverse-event profile was otherwise similar. Eleven patients receiving repaglinide/metformin FDC experienced serious adverse events, although none were considered likely to be related to study medication. One patient (twice daily regimen) with a history of hypertension, hyperlipidemia and coronary artery disease died during the study, which the investigator considered to be probable sudden cardiac death.

No major hypoglycemic episodes were reported in any treatment arm in the 26-week study. The rates of minor hypoglycemic events (defined as plasma glucose levels $<3.1 \mathrm{mmol} / \mathrm{L}$ ) were similar for the two repaglinide/ metformin regimens (3.79 and 4.46 events/patient/year for twice and three times daily, respectively), with over half of the events experienced by only 18 patients. The rate of minor hypoglycemia was significantly lower in the rosiglitazone/ metformin FDC treatment arm (0.27 events/patient/year)

Panel Key features of the prescribing information for PrandiMet ${ }^{\circledR}$ in the USA ${ }^{15}$

\begin{tabular}{ll}
\hline Contraindications & Patients with/receiving: \\
- renal impairment \\
- metabolic acidosis, including diabetes \\
ketoacidosis \\
- both gemfibrozil and itraconazole \\
- - Assess renal function before initiating therapy \\
precautions \\
and at least annually thereafter, and verify as \\
normal \\
receiving iodinated contrast for radiological \\
studies \\
- Do not use in patients with hepatic impairment \\
- Warn patients against excess alcohol intake \\
- Do not use in combination with NPH insulin \\
- Co-administration with gemfibrozil is not \\
recommended \\
- Initiate at the lowest available dose in patients \\
naïve to meglitinide therapy \\
- Measure hematological parameters annually to \\
assess vitamin $\mathrm{B}_{\text {I2 }}$ status \\
- Discontinue use and temporarily initiate insulin \\
if glycemic control deteriorates during periods \\
of stress or if there is decreased intake of fluids \\
and food (eg, infection, surgery) \\
conclusive evidence of macrovascular \\
risk reduction with this or any other oral \\
antidiabetes drug \\
\hline
\end{tabular}

Note: Information is applicable only to treatment within the USA. Abbreviation: NPH, neutral protamine Hagedorn. compared with the twice daily repaglinide/metformin treatment arm (Poisson regression $P=0.0003$ ), but most patients had only approximately 2 events/year. ${ }^{24}$ The higher rate of hypoglycemia with the repaglinide/metformin FDC was not unexpected, as insulin secretagogues have greater hypoglycemic potential than thiazolidinediones. As mentioned earlier, the risk of hypoglycemia with repaglinide/ metformin FDC therapy can be minimized by matching the dose with the correct carbohydrate meal portions and by initiating treatment with lowest available dose in patients naïve to meglitinide therapy. ${ }^{15}$ It is also important to skip medication when meals are skipped. Data from studies in which repaglinide and metformin were used in loose combination are broadly consistent with those from the key FDC trial. ${ }^{12,21,22}$ A higher rate of hypoglycemia was observed with combination therapy compared with repaglinide monotherapy in the study by Moses and colleagues, but none of the events were severe. ${ }^{12}$

As metformin is a component of the FDC, there is an associated risk of lactic acidosis. ${ }^{15}$ However, lactic acidosis was not reported in studies involving combination therapy ${ }^{12,21-24}$ and the incidence of lactic acidosis with metformin overall is rare. ${ }^{33}$ Repaglinide/metformin FDC, as with metformin alone, is contraindicated in patients with renal impairment because metformin is largely excreted by the kidneys. ${ }^{15}$

Additional safety information relating to the use of repaglinide/metformin FDC is provided in country-specific prescribing information. The panel summarizes key points of the prescribing information for the USA.

\section{Patient perspective}

The successful management of type 2 diabetes depends heavily on the behavior of the patients themselves. Oral agents generally compare favorably with injectable therapies used later in the disease process in terms of the perceived burden, but compliance is nonetheless influenced by treatment-related side effects, and the flexibility and convenience of oral antidiabetes regimens. As discussed earlier, the repaglinide/ metformin FDC is generally well tolerated. ${ }^{23}$ Data suggest that both twice and three times daily regimens are weightneutral, ${ }^{23}$ and experience with repaglinide and metformin as monotherapies suggests this will be the case in the longer term. ${ }^{25-27}$ Moreover, starting treatment at the lowest doses in patients naïve to meglitinide therapy and skipping medications when meals are skipped will do much to minimize the risk of hypoglycemia. ${ }^{15}$ 
The diabetes treatment satisfaction questionnaire was used to gather data on patients' satisfaction with repaglinide/ metformin FDC therapy as part of the 26-week study comparing a twice daily repaglinide/metformin FDC regimen with a three times daily regimen and a twice daily rosiglitazone/ metformin FDC regimen. ${ }^{23,24}$ Patients' perceptions of therapy were similar for twice daily repaglinide/metformin and twice daily rosiglitazone/metformin, ${ }^{24}$ and patients were generally more satisfied with the FDC therapies than their previous oral antidiabetes therapies. Perceptions of therapy were similar for the twice and three times daily repaglinide/metformin regimens, except that the three times daily group perceived hypoglycemia and low glucose readings to be more frequent at the end of the study, whereas the twice daily group perceived them to be less frequent. ${ }^{23}$ The frequency of dosing, twice or three times daily, is likely to be considered convenient by most patients. In a study of patient perceptions of repaglinide monotherapy, $18 \%$ of the 1233 patients were taking treatment twice daily with meals and $68 \%$ three times daily with meals. ${ }^{35}$ Overall, $81 \%$ of patients considered treatment to be convenient.

How patients' perceptions of repaglinide/metformin FDC therapy translate into treatment adherence has not been assessed. However, other FDC products have been shown to provide greater patient compliance and thus glycemic control. ${ }^{13,14}$

\section{Conclusions}

The first-line therapy commonly recommended for type 2 diabetes is lifestyle advice in combination with metformin monotherapy. The subsequent failure of therapy is largely due to the progressive nature of type 2 diabetes, with continued deterioration of beta cell function leading to persistent hyperglycemia. The addition of repaglinide to metformin therapy is a rational choice for second-line therapy as the two components have complementary mechanisms of action. Repaglinide is a rapidly absorbed, short-acting insulin secretagogue, which is intended to address mealtime excursions in blood glucose levels. In contrast, metformin is an insulin sensitizer with a longer duration of action, inhibiting hepatic glucose output and increasing peripheral glucose uptake and utilization. Metformin is thus predominantly a basal glucose regulator. The complementary modes of action of repaglinide and metformin suggest that patients with inadequate glycemic control with meglitinide or metformin monotherapy may achieve improved control with repaglinide/ metformin FDC therapy. FDC therapy may additionally be more convenient for patients taking repaglinide and metformin in loose combination.

\section{Acknowledgment}

The author accepts direct responsibility for this paper but is grateful for the contribution made by Watermeadow Medical (supported by Novo Nordisk A/S) in the preparation and revision of the article.

\section{Disclosure}

The author has no conflicts of interest to declare.

\section{References}

1. International Diabetes Federation, 2009. http://www.idf.org/. Accessed December 10, 2009.

2. World Health Organization, 2009. http://www.who.int/diabetes/facts/ world_figures/en/. Accessed December 10, 2009.

3. Levy J, Atkinson AB, Bell PM, McCance DR, Hadden DR. Beta-cell deterioration determines the onset and rate of progression of secondary dietary failure in type 2 diabetes mellitus: the 10-year follow-up of the Belfast Diet Study. Diabet Med. 1998;15:290-296.

4. Rudenski AS, Hadden DR, Atkinson AB, et al. Natural history of pancreatic islet B-cell function in type 2 diabetes mellitus studied over six years by homeostasis model assessment. Diabet Med. 1988;5:36-41.

5. Mitrakou A, Kelley D, Venerman T, et al. Contribution of abnormal muscle and liver glucose metabolism to postprandial hyperglycaemia in NIDDM. Diabetes. 1990;39:1381-1390.

6. Stratton IM, Adler AI, Neil HAW, et al; on behalf of the UK Prospective Diabetes Study Group. Association of glycaemia with macrovascular and microvascular complications of type 2 diabetes (UKPDS 35): prospective observational study. BMJ. 2000;321: 405-412.

7. Haffner SM, Lehto S, Rönnemaa T, Pyörälä K, Laakso M. Mortality from coronary heart disease in subjects with type 2 diabetes and in nondiabetic subjects with and without prior myocardial infarction. N Engl J Med. 1998;339:229-234.

8. Nathan DM, Buse JB, Davidson MB, et al. Medical management of hyperglycemia in type 2 diabetes: a consensus algorithm for the initiation and adjustment of therapy. Diabetes Care. 2009;32:193-203.

9. Rodbard HW, Davidson JA, Garber AJ, Handelsman Y, Lebovitz H, Moghissi ES. Statement by an American Association of Clinical Endocrinologists/American College of Endocrinology consensus panel on type 2 diabetes mellitus: an algorithm for glycemic control. Endocr Pract. 2009;15:540-559.

10. American Diabetes Association. Standards of medical care in diabetes 2009. Diabetes Care. 2009;32 Supp1 1:S13-S61.

11. International Diabetes Federation. Guideline for management of postmeal glucose. Brussels: International Diabetes Federation, 2007. http://www. idf.org/guideline_postmeal. Accessed December 10, 2009.

12. Moses R, Slobodniuk R, Boyages S, et al. Effect of repaglinide addition to metformin monotherapy on glycemic control in patients with type 2 diabetes. Diabetes Care. 1999;22:119-124.

13. Melikian C, White TJ, Vanderplas A, Dezii CM, Chang E. Adherence to oral antidiabetic therapy in a managed care organization: a comparison of monotherapy, combination therapy, and fixed-dose combination therapy. Clin Ther. 2002;24:460-467.

14. Blonde L, Wogen J, Kreilick C, Seymour AA. Greater reductions in A1C in type 2 diabetic patients new to therapy with glyburide/metformin tablets as compared to glyburide co-administered with metformin. Diabetes Obes Metab. 2003;5:424-431.

15. Novo Nordisk, Inc. Prescribing information for PrandiMet (repaglinide and metformin $\mathrm{HCl}$ ) tablets, 2008. www.prandimet.com. Accessed December 10, 2009.

16. Moses R. Fixed combination of repaglinide and metformin in the management of type 2 diabetes. Diabetes Metab Syndr Obes. 2009;2:101-109. 
17. Sambol NC, Brookes LG, Chiang J, et al. Food intake and dosage level, but not tablet vs solution dosage form, affect the absorption of metformin $\mathrm{HCl}$ in man. Br J Clin Pharmacol. 1996;42:510-512.

18. Hoelscher D, Chu PL, Lyness W. Fixed-dose combination tablet of repaglinide and metformin is bioequivalent to concomitantly administered individual tablets of repaglinide and metformin. Clin Drug Invest. 2008;28:573-582.

19. Reilley S, Chang CT, Lyness W. Single-dose pharmacokinetics of a repaglinide/metformin fixed-dose combination tablet in fasted and fed conditions. Diabetes. 2008;57 Suppl 1:A589.

20. Moses R. Achieving glycosylated haemoglobin targets using the combination of repaglinide and metformin in type 2 diabetes: a reanalysis of earlier data in terms of current targets. Clin Ther. 2008;30:552-554.

21. Raskin P, Klaff L, McGill J, et al; for the repaglinide vs nateglinide metformin combination study group. Efficacy and safety of combination therapy: repaglinide plus metformin versus nateglinide plus metformin. Diabetes Care. 2003;26:2063-2068.

22. Reboussin DM, Goff DC, Lipkin EW, et al. The combination and nutritional treatment of late-onset diabetes mellitus (CONTROL DM) trial results. Diabet Med. 2004;21:1082-1089.

23. Raskin P, Lewin A, Reinhardt R, Lyness W, for the repaglinide/ metformin fixed-dose combination study group. Twice-daily and three-times-daily dosing of a repaglinide/metformin fixed-dose combination tablet provide similar glycemic control. Diab Obes Metab. 2009;11:947-952.

24. Raskin P, Lewin A, Reinhardt R, Lyness W; for the repaglinide/ metformin fixed-dose combination study group. Twice-daily dosing of a repaglinide/metformin fixed-dose combination tablet provides glycemic control comparable to rosiglitazone/metformin tablet. Diab Obes Metab. 2009:11:865-873.

25. Wolffenbuttel BH, Landgraf R. A 1-year multicenter randomized double-blind comparison of repaglinide and glyburide for the treatment of type 2 diabetes. Diabetes Care. 1999;22:463-467.

26. Marbury T, Huang WC, Strange P, Lebovitz H. Repaglinide versus glyburide: a one-year comparison trial. Diabetes Res Clin Pract. 1999;43:155-166.
27. Derosa G, Mugellini A, Ciccarelli L, Crescenzi G, Fogari R. Comparison between repaglinide and glimepiride in patients with type 2 diabetes mellitus: a one-year, randomized, double-blind assessment of metabolic parameters and cardiovascular risk factors. Clin Ther. $2003 ; 25: 472-484$

28. Black C, Donnelly P, McIntyre L, Royle P, Shepherd JJ, Thomas S. Meglitinide analogues for type 2 diabetes mellitus. Cochrane Database Syst Rev. 2007, Issue 2. Art.No.:CD004654.DOI: 10.1002/14651858. CD004654.pub2.

29. Salpeter SR, Greyber E, Pasternak GA, Salpeter EE. Risk of fatal and nonfatal lactic acidosis with metformin use in type 2 diabetes mellitus. Cochrane Database Syst Rev. 2006, Issue 1. Art. No.: CD002967. DOI:10.1002/14651858.CD002967.pub2.

30. Owens DR. Repaglinide - prandial glucose regulator: a new class of oral antidiabetic drug. Diabet Med. 1998; 15 Suppl 4:S28-S36.

31. Saenz A, Fernandez-Esteban I, Mataix A, Ausejo M, Roque M, Moher D. Metformin monotherapy for type 2 diabetes mellitus. Cochrane Database Syst Rev. 2005;3:CD002966.

32. Bolen S, Feldman L, Vassy J, et al. Systematic review: comparative effectiveness and safety of oral medications for type 2 diabetes mellitus. Ann Intern Med. 2007;147:386-399.

33. Bristol-Myers Squibb Co. Package insert for Glucophage ${ }^{\circledR}$ (metformin hydrochloride) tablets and Glucophage ${ }^{\mathbb{R}}$ XR (metformin hydrochloride extended-release) tablets 2009 (http://packageinserts.bms.com/pi/ pi_glucophage.pdf; last accessed December 10, 2009).

34. Schramm TK, Gislason G, Vaag A, et al. Differences in risk of cardiovascular death according to type of oral glucose-lowering therapy in patients with diabetes: a nationwide study. Diabetes. 2009;58 Suppl 1:A24.

35. Bonneville M, Colgin J, Nalesnick JA, Perez J, Wentz L. Patient perceptions of prandial oral therapy for type 2 diabetes. Diabetes Educ. 2001;27:659-677.

\section{Publish your work in this journal}

Diabetes, Metabolic Syndrome and Obesity: Targets and Therapy is an international, peer-reviewed open-access journal committed to the rapid publication of the latest laboratory and clinical findings in the fields of diabetes, metabolic syndrome and obesity research. Original research, review, case reports, hypothesis formation, expert opinion and commentaries are all considered for publication. The manuscript management system is completely online and includes a very quick and fair peer-review system, which is all easy to use. Visit http://www.dovepress.com/testimonials.php to read real quotes from published authors. 